\title{
A future perspective in crop protection: chitosan and its oligosaccharides
}

\begin{abstract}
Chitosan and its oligosaccharides have received much interest for potential application in agriculture, biomedicine and biotechnology due to their biocompatibility, biodegradability and bioactivity. Synthetic bactericide treatment has been the main method for controlling diseases, there is a growing international concern over the indiscriminate use of synthetic compounds on crops because of the possible harmful effects on human health and the emergence of pathogen resistance to bactericides. Thus there is a worldwide trend to explore new alternatives in order to reduce the use of synthetic chemical agents. This review focuses on the biological activities of chitosan and its oligosaccharides based on the latest research results. Among the novel families of biological macromolecules, whose relevance is increased in research, are chitosan and chitooligosaccharides (COS). Both become a promising alternative treatment due to its antimicrobial activity. They have a wide scope of application in the food, pharmaceutical, agricultural industries. COS are known to have eliciting activities leading to a variety of defence responses in plants in response to microbial infections to reduce the negative impact of diseases on yield and quality of crops. This review reiterates the properties and uses of chitosan and its oligosaccharides, and focuses on their applications on plant bacterial infections.
\end{abstract}

Keywords: chitosan, chitooligosaccharides (COS), crop, antimicrobial activity
Volume I Issue I - 2014

\author{
Deepmala Katiyar,' A Hemantaranjan,' Bharti \\ Singh, ${ }^{2}$ A Nishant Bhanu ${ }^{3}$ \\ 'Department of Plant Physiology, Banaras Hindu University, India \\ ${ }^{2}$ Department of Microbiology, Banaras Hindu University, India \\ ${ }^{3}$ Department of Genetics \& Plant Breeding, Banaras Hindu \\ University, India
}

\begin{abstract}
Correspondence: A Hemantaranjan, Department of Plant Physiology, Banaras Hindu University, Institute of Agricultural Sciences, Varanasi-22 1005, Uttar Pradesh, India, Tel +05426702939, Email hemantaranjan@gmail.com
\end{abstract}

Received: May 06, 2014 | Published: May 17, 2014

\section{Introduction}

Now-a-day's new approaches and practices are being developed for sustainable agriculture for various crops and vegetables. Therefore, various work is going on chitosan association for different plants growth in various laboratories of India. Chitosan and its oligosaccharides are natural molecule that are applied to crops with the aim of reducing or replacing more costly and environmentally damaging chemical bactericides. With reduced input costs and the potential for increased yields, farmers could gain substantial benefits from these applications of chitosan and its oligosaccharides to crops.

Chitosan is a one of the most abundant natural amino polysaccharides extracted from the exoskeleton of crustaceans and insect, from fungal cell walls, etc. These substances have a wide variety of applications in agricultural and biotechnological industries. ${ }^{1,2}$ Among the novel families of biological macromolecules, whose relevance is becoming increasingly evident, are chitin and its main derivative, chitosan. Both are the simplest linear polysaccharide composed of $\alpha, 1-4$ linked D-glucosamine (GlcN) and N-acetyl-D-glucosamine (GlcNAc) with various compositions of these two monomers. Chitin and its derivatives have become a promising alternative treatment due to its natural character, antifungal activity and elicitation of defense responses in plant tissue. Therefore, recent studies on chitosan have attracted interest in converting it to more soluble COS, which possess a number of interesting biological activities, such as antibacterial and antifungal. ${ }^{3}$ Chitosan and COS have attracted considerable interest due to their biological activities, namely, antimicrobial. ${ }^{4-11}$ and enhanced calcium and ferrum absorption ${ }^{12-17}$ and so on.

Studies on the biological activities of chitosan and its oligomers have been increasing, as no single type of chitosan or its oligomers exerts all of the above bioactivities. Moreover, different chitosan derivatives and enzymatic products have different structures and physicochemical properties, which may result in novel bioactivities or novel findings in known bioactive compounds. Chitosan oligosaccharides also have been shown to induce various plant defense-related cellular responses and possess by themselves antimicrobial properties against a wide spectrum of phytopathogens. ${ }^{18,19}$ The biological activity of COS is known to depend on their structure. Chitosan derivatives have a wide scope of application and regulate the immune system of plants and induce the excretion of resistant enzymes. Moreover, chitosan not only activates the cells, but also improves its disease and insect resistant ability. There is a great concern about the consequences of utilization of chemicals on health and environment, so other means of controlling diseases have become a vehement necessity. There are other wellknown problems in agriculture sector, such as: disease resistance to bactericides, fungicides and high costs to develop new products, so the scientists are interested in biological control agents and naturally occurring fungicides. Keeping in view the important role of chitosan and $\operatorname{COS}$ in agriculture, this review is aimed at investigating the efficacy of chitosan and its derivative on crop protection.

\section{Chitosan}

Chitosan is derived from chitin, a polysaccharide found in exoskeleton of shellfish such as shrimp, lobster or crabs and cell wall of fungi. ${ }^{20}$ Chitosan poly $(1,4)-2$-amino- 2 -deoxy- $\beta$-D glucose, is a deacetylation product of chitin, a polysaccharide second by the prevalence in nature after cellulose. ${ }^{21}$ Chitin is an abundant natural polysaccharide produced by arthropods and crustaceans. It is found in the wide number of invertebrates (crustacean's exoskeleton, insect's cuticles) and it is also an ingredient of cell walls in fungi yeast and algae and as a structural polysaccharide in basidiomycetes and filamentous fungal cell walls, constituting almost $16 \%$ of 
the dry weight of the organism. ${ }^{22}$ Chitosan is the simplest linear polysaccharide composed of $\alpha, 1-4$ linked D-glucosamine $(\mathrm{GlcN})$ and N-acetyl-D-glucosamine (GlcNAc) with various compositions of these two monomers. ${ }^{1}$ Chitosan are highly basic polysaccharides with unique properties like the ability to form films ${ }^{23}$ to react with polyanions ${ }^{24}$ as well as to chelate and remove metal ions. ${ }^{25}$ The positive charge of chitosan confers to this polymer numerous and unique physiological and biological properties with great potential in a wide range of industries such as cosmetology (lotions, hair additives, facial and body creams), ${ }^{26}$ food (coating, preservative, antioxidant, antimicrobial), ${ }^{27-32}$ biotechnology (chelator, emulsifier, flocculent) ${ }^{9,33}$ pharmacology and medicine (fibers, fabrics, drugs, membranes, artificial organs) ${ }^{34-36}$ and agriculture (soil modifier, films, fungicide, elicitor)..$^{37-40}$ The molecular weight has important effect on the biological activity and absorption of chitosans in vivo. ${ }^{41-43}$ Chitosan and its derivatives have shown various functional properties and made them possible to be used in many fields including, food, ${ }^{44}$ cosmetics ${ }^{2}$ biomedicine, ${ }^{45}$ agriculture, ${ }^{46}$ environmental protection ${ }^{47}$ and wastewater management. ${ }^{48}$ Further, the biodegradable, ${ }^{49}$ nontoxic ${ }^{50}$ and non-allergenic features of chitosan especially encourage its potential use as a bioactive material. ${ }^{51}$

The Food and Drug Administration (FDA) agency in U.S. approved chitosan as a feed additive in 1983. Chitosan has been widely applied in functional food environmental protection and biotechnology. ${ }^{52,53}$ Chitosan has been reported to have antifungal and antimicrobial effects. ${ }^{54,55}$ Chitosan is a static or cidal agent of microbial growth, useful in agriculture, household goods manufacturing ${ }^{4}$ and the applications and mode of action have been reviewed. ${ }^{56}$ Stimulation of plants immunity against microorganisms (bacteria and fungi). ${ }^{57-61}$ It suppresses the growth of bacteria probably because of binding to the cell surface. ${ }^{9}$ Recently, some researchers reported that chitosan enhanced plant growth and development. ${ }^{60,62,63}$ The molecular weight has important effect on the biological activity and absorption of chitosan in vivo. ${ }^{41,42}$ Lee et al. ${ }^{64}$ reported that chitosan reduced the size of stomatal aperture and inhibited light induced stomatal opening by inducing reactive oxygen species (ROS) including super oxide and hydrogen peroxide which inhibit stomatal opening and promote stomatal closing.

\section{Source}

Chitin and chitosan are found as supporting materials in many aquatic organisms (shells of shrimps, crabs, bone plates of squids and cuttlefishes), in many insects (mosquitoes, cockroaches, honey bees, silkworms, Drosophila melanogaster, Extatosoma tiaratum and Sipyloidea sipylus), in terrestrial crustaceans (Armadillidium vulgare, Porcellio scaber), in nematode, in mushrooms (Agaricus bisporus, Auricularia auriculajudae, Lentinula edodes, Trametes versicolor, Armillaria mellea, Pleurotus ostreatus, Pleurotus sajo-caju and Pleurotus eryngii) and in some microorganisms (yeast, fungus and algae diatom). ${ }^{65-69}$

\section{Chitosan application on crops}

Chitosan effects on plant response were first characterized as an elicitor. It was shown to be able to activate plant defensive genes through the octadecanoid pathway. ${ }^{70}$ According to the defensive gene induction activity, chitosan was proved to induce disease resistance in several plants, with pathogen and plant cultivar specificity. ${ }^{71,72}$ Chitosan was also involved in the stomatal response where stomatal opening provides access to inner leaf tissue for plant pathogens, so narrowing stomatal apertures may be advantageous for plant defense. The stomatal aperture of tomato and Commelina communis was reduced when the epidermis was treated with chitosan. ${ }^{64}$ It was found in pepper plant that foliar application of chitosan decreased transpiration and reduced water use by $26-43 \%$, while maintained biomass production and yield. Hence, chitosan might be an effective antitranspirant to conserve water use in agriculture. ${ }^{73}$ Hirano et al. ${ }^{74}$ reported that coating of seeds with depolymerized chitosan or its oligosaccharides typically increased the chitinase activity in seedlings by $30-50 \%$, unless the seeds had a hard cuticle. Low molecular weight of chitosan $(5 \mathrm{kDa})$ induced the accumulation of phytoalexins in plant tissue, decreased the total content and changed the composition of free sterols producing adverse effects on infesters, activated chitinase, beta-glucanase, lipoxygenases and stimulating the generation of reactive oxygen species. ${ }^{75}$

Application of chitin and chitosan to soybean leaf tissues increased activities of Phenylalanine Ammonia Lyase (PAL) and Tyrosine Ammonia-Lyase (TAL). The elevation of PAL and TAL activity was dependent on the chain length of the oligomers and time after treatment. ${ }^{76}$ Xianling et al., ${ }^{77}$ indicated that seeds of mulberry cultivar were coated with chitosan solution at 3\% prepared from silkworm chrysalises increased the respiration rate of germination seeds, root vigor, chlorophyll, protein content and peroxidase in seedlings as well as nitrate reductase and amylase activities. Nichoson et al. ${ }^{78}$ reported that increases in PAL activity have been demonstrated to be one of the earliest responses of plants to the onset of stress by pathogen infection and are considered as an indication of resistance. Since PAL is the key enzyme in the phenylpropanoid pathway, its activity leads to synthesis of phenols, which are compounds associated with expression of resistance.

Yue et al., ${ }^{79}$ studied maize seeds and reported that chitosan concentration at $2-4 \mathrm{~g} /$ litre resulted in a positive effect on endogenous hormone content, alpha-amylase activity and chlorophyll content in seedling leaves. Khan et al., ${ }^{62}$ found that on the first day after foliar application, chitosan pentamer decreased the net photosynthetic rate of maize and subsequently there was an increase on day 3 of $10-18 \%$ over the control. This increase was related with the increases in stomatal conductance and transpiration rate, while the intercellular $\mathrm{CO}_{2}$ concentration was not different from the control plants. Chitosan also enhanced the Rice Endosperm Kinase (REK) in RNA expression, which was completely abolished at either 12 or $24 \mathrm{~h}$ by cycloheximide. However, high/low temperature and the environmental pollutants, ozone and sulfur dioxide, failed to enhance the REK mRNA expression, as determined using in vivo system. These results strongly indicated a function for REK in defense/stress responses in rice photosynthetic tissues. ${ }^{80}$ Ohta et al.,${ }^{81}$ reported that chitosan application to the soil at sowing time remarkably enhanced plant growth and flowered 15 days earlier than the control. Moreover, a greater number and weight of flowers were produced by chitosan application. Rapeseed (Brassica chinensis) coated with small molecular weight chitosan showed positive effects on germination index, growth of seedlings and root length. ${ }^{82}$ Chibu and Shibayama ${ }^{83}$ studied chitosan application on early growth of four crops: soybean, lettuce, tomato and rice. The results showed that chitosan at 0.1 or $0.5 \%$ increased leaf area, leaf dry weight and leaf length of soybean, lettuce and rice whereas chitosan at $0.1 \%$ showed positive effects on leaf area, leaf length and dry weight of tomato. Seeds of non- heading chinese cabbage cv. Dwarf hybrid No.1 dressed with chitosan at the rate $0.4-0.6 \mathrm{mg} / \mathrm{g}$ of seeds and leaf spraying with $20-40 \mathrm{microgram} / \mathrm{ml}$ increased total fresh weight, leaf 
area, plant height, root length, soluble protein and soluble sucrose in leaves, while the content of crude fiber decreased. ${ }^{84}$

Utsunomiya et al. ${ }^{85}$ studied the effect of using chitosan oligosaccharides as a soil conditioner with high and low nitrogen on the flowering and fruit growth of purple passion fruit. They found that the numbers of flowers, harvested fruits, fruit weight and juice production were increased significantly by the soil conditioner under high nitrogen. Under conditions of low nitrogen, the soil conditioner reduced flower formation in the first growing season but had little effect on flowering in the next season. This treatment increased fruit and juice weights to nearly the same degree as those observed in the high nitrogen without soil conditioner.

Harada et al. ${ }^{86}$ reported that application of chitosan in the field increased shoot growth, branch length, node number per plant and seed yield of soybean and total root length per plant increased by chitosan application in the pot experiment. Krivtsov et al., ${ }^{87}$ found that wheat seed soaked with aqueous solution of polymer (10-20kDa) or oligomer $(2-4 \mathrm{kDa})$ at concentration of $50 \mathrm{mg} /$ litre for 3 to 18 hours increased stem and root lengths of seedling by six days after seed treatment. Foliar application at the panicle initiation stage with 0.01 or $0.02 \%$ solution of oligochitosan two times (five days apart) increased spike weight, 1,000 -grain weight and grain yield by $16 \%$. Ali et al., ${ }^{88}$ revealed that the production of nodule fresh weight and nitrogen fixation of soybeans decreased at early growth stage (28days after sowing) in soil supplemented with chitosan $0.1-0.25 \%$, but increased at the later growth stage. Chibu and Shibayama ${ }^{83}$ reported that the top dry weight, leaf area, number of first order thick lateral and second order lateral roots of radish seedlings were increased by chitosan application at $0.1 \%$. Seed of soybeans soaked with chitosan solution at $1000 \mathrm{ppm}$ for six hours and cultured at 25 degree $\mathrm{C}$ for 6 days increased germination percentage, hypocotyl thickness, total length and fresh weight of sprouts by $4,5,2$ and $1 \%$ respectively. ${ }^{64}$

Chitosan has been shown to trigger defense mechanisms in plants. Plants treated with chitin and chitosan produce chitinase that breaks down the chain of chitin and chitosan into more soluble form. Loschke et al. ${ }^{89}$ reported that chitosan induces the expression of a variety of genes involved in plant defense response that, in some cases, result in increased synthesis of secondary plant metabolites. Chitosan influences pathways involving jasmonic acid..$^{70,90,91}$ Jasmonate exhibits some activities similar to the plant hormone Abscisic Acid (ABA), which plays a key role in the regulation of water use by plants. ${ }^{92}$ Increased levels of ABA result in closure of the plant's stomata and reduced transpiration. ${ }^{93,94}$ Thus, manipulating the ABA signaling pathway offers the possibility to reduce water consumption by plants..$^{95}$ Jwa et al. ${ }^{96}$ reported that as a fungal elicitor, chitosan enhanced the Rice Endosperm Kinase (REK) mRNA expression, which responds to the critical signals mediating plant self defense/stress response, namely Jasmonic Acid (JA), Salicylic Acid (SA) and hydrogen peroxide. Klusener et al., ${ }^{97}$ revealed that yeast (Saccharomyces cerevisiae) elicitor and chitosan, both elicitors of plant defense response, activated this current activation requiring cytosolic NADPH and induced elevations in the concentration of free cytosolic calcium and stomatal closure in guard cells. Wheat and barley damaged at $2.5 \mu \mathrm{g} /$ $\mathrm{ml}$ of vanadium were recovered by treatment with $10-100 \mu \mathrm{g} / \mathrm{ml}$ chitosan. ${ }^{98}$ Lee et al. ${ }^{64}$ reported that chitosan, a component of fungal cell walls, reduced the size of stomatal aperture and inhibited light induced stomatal opening in tomato epidermis by inducing Reactive Oxygen Species (ROS) such as superoxide and $\mathrm{H}_{2} \mathrm{O}_{2}$, which inhibit stomatal opening and promote stomatal closing.

\section{Chit oligosaccharides}

Chitooligosaccharides (COS) has attracted considerable interest due to their biological activities, namely, antimicrobial. ${ }^{5-11}$ Studies on the biological activities of chitosan and its oligosaccharides have been increasing, as no single type of chitosan or its oligomers exerts all of the above bioactivities. Moreover, different chitosan derivatives and enzymatic products have different structures and physicochemical properties, which may result in novel bioactivities or novel findings in known bioactive compounds. Due to its cationic character, chitosan presents a wide variety of physicochemical and biological properties, including antimicrobial, antioxidant and antihypertensive properties. ${ }^{99}$ These properties make it suitable for numerous applications in different fields, for instance, medicine (pharmacology, cosmetics), biotechnology, agriculture, the food industry (nutritional enhancement and food processing), the environment (waste and water treatment) and the textile industry. ${ }^{99,100}$ In addition, its lack of toxicity and allergenicity, as well as its biocompatibility, biodegradability and bioactivity makes it a very attractive substance for use in biomaterial design. However, its poor solubility in solutions of neutral and basic $\mathrm{pH}$ hinders its use in many industrial applications. Therefore, there is considerable interest in improving chitosan solubility and different strategies have been developed for instance, the partial hydrolysis of chitosan to obtain Low Molecular Weight Chitosan (LMWC) and COS, which are soluble in water. COS are defined as chitosan with a Degree of Polymerization (DP) less than 20 and MW of up to 3900Da. ${ }^{3,54,101,102}$

Hydrolysis of chitosan can be carried out by chemical, physical and enzymatic methods. Chemical hydrolysis is performed at high temperatures under highly acidic conditions, mainly using $\mathrm{HCl}$ or $\mathrm{HNO}_{2}$ and produces a large amount of glucosamine. ${ }^{103}$ Due to the complexity of controlling the progress of the reaction, these treatments also result in the formation of secondary compounds that are difficult to remove. By physical methods such as irradiation with low-frequency ultrasound $(20 \mathrm{kHz})$, partial depolymerization is obtained, reducing the average MW from $2000 \mathrm{kDa}$ down to $450 \mathrm{kDa}$ or from $300 \mathrm{kDa}$ to $50 \mathrm{kDa}$; however, the reduction of MW is limited. ${ }^{102}$ Enzymatic methods, such as the use of chitosanases and nonspecific enzymes, seem to be generally preferable to chemical methods because the reaction is performed under more gentle conditions and the MW distribution of the product is more controllable. The expensive cost of chitosanases limits their wide application on an industrial scale, even using immobilized enzymes. ${ }^{104}$ On the other hand, nonspecific enzymes are inexpensive and commercially available and have been used in the industry for years to produce COS with relatively low cost. Lin et al., ${ }^{105}$ reported the hydrolytic susceptibility of chitosan to a wide range of enzymes, including glycanases, proteases and lipases derived from bacterial, fungal, mammalian and plant sources. Enzymatic chitosan hydrolysis can be performed either with soluble or immobilized enzymes column or membrane reactors. Certain chitosan oligomers have physiological functions including the induction of phytoalexins. ${ }^{106}$

\section{Antimicrobial activity}

The antimicrobial activity of chitosan and its oligosaccharide derivative has been recognized and is considered to be one of the most important properties, corresponding directly to their possible biological applications. ${ }^{10,107}$ Allan et al., ${ }^{4}$ first reported chitosan and its derivatives had broad-spectrum antimicrobial effects. Since then many studies have been performed on the antimicrobial activity of 
chitosan and its derivatives and oligosaccharides, confirming that chitosan showed antimicrobial properties with bacteria, yeasts and fungi. The antibacterial activities of six chitosans and six chitosan oligomers with different molecular weights $(\mathrm{Mw})$ were examined against four gram-negative (Escherichia coli, Pseudomonas fluorescens, Salmonella typhimurium and Vibrio parahaemolyticus) and seven gram-positive bacteria (Listeria monocytogenes, Bacillus megaterium, Bacillus cereus, Staphylococcus aureus, Lactobacillus plantarum, Lactobacillus brevis and Lactobacillus bulgaricus) by No et al. ${ }^{6}$ They found that chitosan showed higher antibacterial activities than chitosan oligomers and markedly inhibited the growth of most of the tested bacteria, although the inhibitory effects differed with the $\mathrm{Mw}$ of chitosan and the bacterial species. Chitosan generally showed stronger bactericidal effects on gram positive bacteria than gramnegative bacteria at a concentration of $0.1 \%$. The minimum inhibitory concentration (MIC) of chitosan ranged from $0.05 \%$ to more than $0.1 \%$ depending on the bacterial species and the Mw of the chitosan. As a chitosan solvent, $1 \%$ acetic acid was effective in inhibiting the growth of most tested bacteria except for Lactobacillus, which was more effectively suppressed with $1 \%$ lactic or formic acids. The antibacterial activity of chitosan ranged from $0.05 \%$ to more than $0.1 \%$ depending on the bacterial species and the Mw of the chitosan. As a chitosan solvent, $1 \%$ acetic acid was effective in inhibiting the growth of most tested bacteria except for Lactobacillus, which was more effectively suppressed with $1 \%$ lactic or formic acids.

The antibacterial activity of chitosan was inversely affected by $\mathrm{pH}$ and exerted better effects at a lower $\mathrm{pH}$ value. Uchida et al., ${ }^{9}$ previously reported that the MIC of chitosan for E. coli and $S$. aureus were $0.025 \%$ and $0.05 \%$, respectively. Hence, chitosan was recognized as the best candidate among natural antimicrobial preservatives, although the antimicrobial activity and MIC acquired from different researchers differs, probably due to differences in the experimental methods, type of chitosan or $\mathrm{pH}$. However, Zheng et al., ${ }^{108}$ used E. coli and $S$. aureus to study the antimicrobial activity of chitosan with different molecular weights $(\mathrm{Mw})$. They found that chitosan with Mw below $300 \mathrm{kDa}$, the antimicrobial effect on S. aureus was strengthened as the molecular weight increased; in contrast, the effect on $E$. coli was weakened. The antibacterial activities of watersoluble N-alkylated disaccharide chitosan derivatives against $E$. coli and $S$. aureus were also investigated by Yang et al. ${ }^{109}$ They found that the antibacterial activity of chitosan derivatives was affected by the degree of Disaccharide Substitution (DS) and the kind of disaccharide present in the molecule. Regardless of the kind of disaccharide linked to the chitosan molecule, a DS of $30-40 \%$, in general, exhibited the most pronounced antibacterial activity against both test organisms. $E$. coli and $S$. aureus were the most susceptible to cellobiose chitosan derivatives and maltose-chitosan derivatives, both with DS values of $30-40 \%$, among the various examined chitosan derivatives. Although the disaccharide chitosan derivatives showed less antibacterial activity than native chitosan at $\mathrm{pH} 6.0$, they exhibited higher activity at $\mathrm{pH} 7.0$. The antibacterial activity of the chitosan derivatives (DS 30-40\%) against $E$. coli increased as the $\mathrm{pH}$ increased above 5.0 and reached a maximum around $\mathrm{pH} 7.0-7.5$. The effect of $\mathrm{pH}$ on the antibacterial activity of chitosan derivatives against $S$. aureus was not as significant as that observed with $E$. coli. Population reductions of $E$. coli or $S$. aureus in nutrient broth increased markedly when the concentration of chitosan derivatives was increased from 0 to $500 \mathrm{mg} / \mathrm{kg}$, while no marked increase in population reduction was found with further increases, even up to $2,000 \mathrm{mg} / \mathrm{kg}$. Additionally, chitosan has shown inhibitory effects on the growth of fungi and other microorganisms, especially plant pathogens. Chitosan can induce plants to produce defence enzymes (chitosanases) with antimicrobial activity. It has a higher antimicrobial activity than chitin because it carries a positive charge.

Hirano et al. ${ }^{33}$ studied the relative molecular weights of chitosan on the inhibition of plant pathogens. The results indicated that COS (DP2-8) and partially degraded Low Molecular Weight Chitosan (LMWC) showed higher inhibitory activities on Fusarium oxysporum, Phomopsis fukushi and Alternaria alternata than high-molecularweight chitosan. Uchida et al. ${ }^{9}$ found that the inhibition of fungi and bacteria by COS with higher Degrees of Polymerization (DP) was much stronger than those by chitosan and COS with lower DP; simultaneously, their inhibitory effects increased with increasing DD. This result was confirmed by later research. ${ }^{110}$ Jeon et al., ${ }^{14}$ produced and isolated three kinds of COS using an ultra filtration membrane bioreactor; among these, the COS with $\mathrm{Mw}$ of 5,000-10,000 showed strong antimicrobial activity on the tested pathogens. Later, they produced a COS with a DP of 3-6 by the same methods, which showed a higher inhibitory effect on $E$. coli with increasing concentration; a $0.5 \%$ COS solution completely inhibited the growth of $E$. coli. In our previous study, we also studied the antimicrobial activity of partially hydrolyzed COS against the common bacteria, molds and yeasts in found food and found it to be much higher than that of chitosan, with an MIC of $1-10 \mathrm{~g} / \mathrm{L}$ and the inhibitory effects were enhanced with increasing COS concentration. Moreover, the relations between their structures and antimicrobial effects were also examined. It was found that the antimicrobial activity of COS was correlated with the content of protonated amino groups and relative molecular weights. Additionally, when COS was applied as a preservative in apple juice, the storage period of juice at $37^{\circ} \mathrm{C}$ was prolonged from nine days to 70 days with a $\mathrm{COS}$ concentration of $4 \mathrm{~g} / \mathrm{L}$, showing good preservative effects. ${ }^{10}$ Chitin, chitosan and their oligomers have been reported to exhibit elicitor activities in several plants and have been widely used as elicitors for the induction of secondary products in plant cell cultures. When attacked by pathogens such as fungi, bacteria and viruses, higher plants have various defense reactions including the production of phytoalexins, enzymes such as chitinase and $\beta$ glucanase, proteinase inhibitors, hydroxyproline-rich glycoproteins, proteinase, active oxygen species as well as lignification. Chitin oligomers were active as elicitors of defense reactions in higher plants, whereas chitosan oligomers had almost no eliciting activity. However, higher chitosan oligomers, e. g., octamers, were efficient elicitors for inducing pisatin accumulation and inhibiting fungal growth. These results suggest that elicitor activities of chitosan oligomers are highly dependent on their polymerization and the presence of N-acetyl glucosamine. From the above, we can conclude that although there are many reports discussing chitosan's antimicrobial activity in different conditions with conflicting results, they all confirmed that chitosan and its oligosaccharides have strong antimicrobial effects and are safe for human use. Hence, the antimicrobial characteristics chitosan and its oligosaccharides present a profitable potential for developing natural food preservatives for food-processing applications and functional-food additives.

\section{Conclusion}

After various recent research findings, chitosan has applications in numerous fields, as described in many review articles. This naturally occurring molecule with interesting antimicrobial and 
eliciting properties has been getting more attention in recent years. This molecule can be used in a number of ways to reduce plant disease levels and prevent the development and spread of diseases, thus preserving crop yield and quality. The potent effect of chitosan on plant diseases control is from its antimicrobial properties and plant innate immunity elicited activity. The antimicrobial activity is influenced by several factors, such as MW, DDA, solubility, positive charge density, chemical modification, $\mathrm{pH}$, concentration, chelating capacity and type of micro-organism. Chitosan has also become a postharvest promising treatment for fruits due to its natural character, antimicrobial activity and elicitation of defence responses. In spite of the chitosan advantages, the poor solubility of chitosan is the major limiting factors in its utilization. Therefore, several researchers have started to modify a chitosan molecule to produce high-antimicrobial active derivatives COS. Our review suggests that chitosan and COS can be used as potent antibacterial molecule in biological systems.

\section{Future perspectives}

Our review revealed that chitosan and COS have a potential to develop an alternative bactericide to prevent plant infections. Interesting theoretical and applied findings were gathered in recent years, whereas more are needed to examine the mechanisms governing the mode of action of these compounds. In the case of antimicrobial mode of action, future work should aim at clarifying the molecular details of the underlying mechanisms and their relevance to the antimicrobial activity of chitosan. In addition, participation and collaboration of research institutes, industry and government regulatory agencies will be the key for the success of the antimicrobial mechanism when applied in large scales. Therefore, future research should be directed towards understanding their molecular level details, which may provide insights into the unknown biochemical functions of chitosan and COS as well as help to accelerate their future and might assist in the goal of sustainable agriculture.

\section{Acknowledgements}

The Authors wish to thank University Grant Commission (UGC, Government of India) New Delhi for financial support in form of Post Doc Fellowship (F.15-1/2012-13/PDFWM-2012-13-OB-UTT17432). We are thankful to Department of Plant physiology, Institute of Agricultural Sciences, Banaras Hindu University, Varanasi, as well as Prof. A. Hemantaranjan for providing necessities of this work.

\section{Conflict of interest}

The author declares no conflict of interest.

\section{References}

1. Brine CJ, Sandford PA, Zikakis JP. Advances in chitin and chitosan London: Elsevier Science Publishers; 1992. 685 p.

2. Majeti NA, Kumar R. A review of chitin and chitosan applications. React Funct Polym. 2000;46(1):1-27.

3. Jeon YJ, Park PJ, Kim SK. Antimicrobial effect of chitooligosaccharides produced by bioreactor. Carbohyd Polym. 2001;44(1):71-76.

4. Allan CR, Hadwiger LA. The fungicidal effect of chitosan on fungi of varying cell wall composition. Experimental Mycology. 1979;3(3):285287.

5. Kendra DF, Hadwiger LA. Characterization of the smallest chitosan oligomer that is maximally antifungal to Fusarium solani and elicits pisatin formation in Pisum sativum. Experimental Mycology. 1984;8(3):276-281.
6. No HK, Park NY, Lee SH, et al. Antibacterial activity of chitosans and chitosan oligomers with different molecular weights. International Journal of Food Microbiology. 2002;74(1-2):65-72.

7. Sekiguchi S, Miura Y, Kaneko H, et al. Molecular weight dependency of antimicrobial activity by chitosan oligomers. Food hydrocolloids. 1993. p. 71-76.

8. Sudarshan NR, Hoover DG, Knorr D. Antibacterial action of chitosan. Food Biotechnol. 1992;6(3):257-272.

9. Uchida Y, Lzume M, Ohtakara A. Preparation of chitosan oligomers with purified chitosanase and its application. In Skjak-Brak G, et al. editors. Chitin and Chitosan:Sources, chemistry, biochemistry, physical properties and applications. London: Elsevier; 1989. p. 373-382.

10. Wei XL, Xia WS. Research development of chitooligosaccharides physiological activities. Chinese Pharmaceutical Bulletin. 2003;19(6):614 617.

11. Zhao XR, Xia WS. Antimicrobial activities of chitosan and application in food preservation. Chinese Food Research and Development. 2006;27(2):157-160.

12. Bravo-Osuna I, Millotti G, Vauthier C, et al. In vitro evaluation of calcium binding capacity of chitosan and thiolated chitosan poly (isobutyl cyanoacrylate) core-shell nanoparticles. International Journal of Pharmaceutics. 2007;338(1-2):284-290.

13. Deuchi K, Kanauchi O, Shizukuish M, et al. Continuous and massive intake of chitosan affects mineral and fat-soluble vitamin status in rats fed on a high-fat diet. Bioscience Biotechnology and Biochemistry. 1995;59(7):1211-1216.

14. Jeon YJ, Kim SK. Production of chitooligosaccharides using an ultra filtration membrane reactor and their antibacterial activity. Carbohydr Polym. 2000;41(2):133-141.

15. Jung WK, Moon SH, Kim SK. Effect of chitooligosaccharides on calcium bioavailability and bone strength in ovariectomized rats. Life Science. 2006;78(9):970-976.

16. Liao FH, Shieh MJ, Chang NC, et al. Chitosan supplementation lowers serum lipids and maintains normal calcium, magnesium, and iron status in hyperlipidemic patients. Nutrition Research. 2007;27(3):146-151.

17. Sinswat P, Tengamnuay P. Enhancing effect of chitosan on nasal absorption of salmon calcitonin in rats:comparison with hydroxypropyl- and dimethyl-b-cyclodextrins. International Journal of Pharmaceutics. 2003;257(1-2):15-22.

18. MG Hahn. Microbial elicitors and their receptors in plants. Annu Rev Phytopathol. 1996;34:387-412.

19. Barber MS, Bertram RE, Ride JP. Chitin oligosaccharides elicit lignification in wounded wheat leaves. Physiol Mol Plant. 1986;34(1):3-12.

20. Wojdyla AT. chitosan in the control of rose disease:six years trials. Bull Polish Acad Sci Biol Sci. 2001;49:233-252.

21. Rinaudo M. Chitin and chitosan:Properties and application. Prog Polym Sci. 2006;31(7):603-632

22. Muzzarelli RAA. Chitin nanostructures in living organisms. In Chitin Formation and Diagenesis. 2010;34:1-34.

23. Yusof NL, Lim LY, Khor E. Flexible chitin films:structural studies. Carbohydr Res. 2004;339(16):2701-2711.

24. Acosta N, Aranaz I, Peniche C, et al. Tramadol release from a delivery system based on alginate-chitosan microcapsules. Macromol Biosci. 2003;3(10):546-551

25. Bhatnagar A, Sillanpaa M. Applications of chitin and chitosan derivatives for the detoxification of water and waste water-a short review. $A d v$ Colloid Interface Sci. 2009;152(1-2):26-38. 
26. Lang G, Clausen T. The use of chitosan in cosmetics. In:Skjak-Braek $\mathrm{G}$, et al. editors. Chitin and Chitosan, Sources, Chemistry, Biochemistry. Physical Properties and Applications. Elsevier Applied Science; 1989. p. 139-147.

27. Sapers GM. Chitosan enhances control of enzymatic browning in apple and pear juice by filtration. J Food Prot. 1992;57(5):1192-1193.

28. Pennisi E. Sealed in plastic edible film. Sci News. 1992;141:12-13.

29. Fang S, Li CF, Shih C. Antifungal activity of chitosan and its preservative effect on low-sugar candied kumquat. J Food Prot. 1994;56:136-140.

30. Roller S, Covill N. The antifungal properties of chitosan in laboratory media in apple juice. Int J Food Microbiol. 1999;47(1-2):67-77.

31. Benjakul S, Visessanguan W, Tanaka M, et al. Effect of chitin and chitosan on gelling properties of surimi from barred garfish (Hemiramphus far). J Sci Food Agric. 2000;81(1):102-108.

32. Shahidi F, Kamil JK, Jeon YJ, et al. Antioxidant role of chitosan in a cooked cod (Gadus Morhua) model system. J Food Lipids. 2002;9(1):5764.

33. Hirano S, Nagao N. Effects of chitosan, pectic acid, lysozyme, and chitinase on the growth of several phytopathogens. Agri and Biol Chem. 1989;53(11):3065-3066.

34. Kulpinsky P, Nishimura SI, Tokura S. Preparation and characterization of functionalized chitosan fibers. Adv Chitin Sci. 1997;2:334-338.

35. Nishimura Y. Physiological effects of chitosan administered for long period. Food Style. 1997;21:50-52.

36. Liu XD, Nishi N, Tokura S, et al. Chitosan coated cotton fiber:preparation and physical properties. Carbohydr Polym. 2001;44(3):233-238.

37. Hoagland PD, Parris N. Chitosan/pectin laminated films. J Agric Food Chem. 1996;44(7):1915-1919.

38. Lafontaine PJ, Benhamou N. Chitosan treatment:an emerging strategy for enhancing resistance of greenhouse tomato plants to infection by Fusarium oxysporum f. sp. radicis-lycopersici. Biocontrol Sci Technol. 1996;6(1):111-124.

39. Makino Y, Hirata T. Modified atmosphere packaging of fresh produce with a biodegradable laminate chitosan-cellulose and polycaprolactone. Postharvest Biol Technol. 1997;10(3):247-254.

40. Ren H, Endo H, Hayashi T. Antioxidative and antimutagenic activities and polyphenol content of pesticide-free and organically cultivated green vegetable using water-soluble chitosan as a soil modifier and leaf surface spray. J Sci Food Agric. 2001;81(15):1426-1432.

41. Chae SY, Jang MK, Nah JW. Influence of molecular weight on oral absorption of water soluble chitosans. Journal of Controlled Release. 2005;102(2):383-394.

42. Zeng LT, Qin CQ, Wang W, et al. Absorption and distribution of chitosan in mice after oral administration. Carbohydrate Polymers. 2008;71(3):435-440.

43. Tanaka Y, Tanioka S, Tanaka M, et al. Effect of chitin and chitosan particles on BALB/c mice by oral and parenteral administration. Biomaterials. 1997;18(8):591-595.

44. Shahidi F, Synowiecki J. Isolation and charactrization of nutrients and value-added products from snow crab (Chinoecetes opilio) and shrimp (Pandalus borealis) processing discards. J Agric Food Chem. 1991;39(8):1527-1532.

45. Felt O, Buri P, Gurny R. Chitosan:a unique polysaccharide for drug delivery. Drug Dev Ind Pharm. 1998;24(11):979-993.
46. Yamada T, Shibuya N, Kodama O, et al. Induction of phytoalexin formation in suspension-cultured rice cells by N-acetyl-chitooligosaccharides. Biosci Biotech Biochem. 1993;57:405-409.

47. Peniche-covas C, Alwarez LW, Arguelles-Monal W. The adsorption of mercuric ions by chitosan. Journal of Applied Polymer Science. 1992;46(7):1147-1150.

48. Jeuniaux C, Almas KA, Baradarajan A, et al. Chitosan as a tool for the purification of waters. Chitin in nature and technology. 1986;551-570.

49. Borchard G, Junginger HE. Modern drug delivery applications of chitosan. Adv Drug Del Rev. 2001;52(2):103.

50. Karlsen J, Skaugrud O. Excipient properties of chitosan. Manuf Chem. 1991;62:18-19.

51. Kurita K. Chemistry and application of chitin and chitosan. Polymer Degradation and Stability. 1998;59(1-3):117-120.

52. Shahidi F, Arachchi JKV, Jeon YJ. Food applications of chitin and chitosans. Trends Food Sci Technol. 1999;10:37-51.

53. Rungsardthong V, Wongvuttanakul N, Kongpien N, et al. Application of fungal chitosan for clarification of apple juice. Process Biochemistry. 2006;41(3):589-593.

54. Vishu Kumar AB, Varadaraj MC, Gowda LR, et al. Characterization of chito-oligosaccharides prepared by chitosanolysis with the aid of papain and Pronase, and their bactericidal action against Bacillus cereus and Escherichia coli. Biochem J. 2005;391(2):167-175.

55. Xing R, Yu H, Liu S, et al. Antioxidative activity of differently regioselective chitosan sulfates in vitro. Bioorganic and Medicinal Chemistry. 2005;13(4):1387-1392.

56. Rabea EI, Badawy MET, Stevens CV, et al. Chitosan as antimicrobial agent:applications and mode of action. Biomacromolecules. 2003;4(6):1457-1465.

57. ChunYan L, GuoRui M, WenYing H. Induction effect of chitosan on suppression of tomato early blight and its physiological mechanism. $J$ Zhejiang Univ Agric Life Sci. 2003;29:280-286.

58. Patkowska E, Pieta D, Pastucha H. The effect of biochikol 020 pc on microorganisms communities in the rhizosphere of Faba bean plants. Polish Chitin Sco Monograph. 2006;11:171-178.

59. No HK, Meyers SP, Prinyawiwatkul W, et al. Applications of chitosan for improvement of quality and shelf life of foods:a review. J Food Sci. 2007;72(5):87-100.

60. Gornik K, Grzesik M, Duda BR. The effect of chitosan on rooting of gravevine cuttings and on subsequent plant growth under drought and temperature stress. J Fruit Ornamental Plant Res. 2008;16:333-343.

61. Serei A, Neven A, Abd-El-Aal S, et al. The mutagenic activity and its effect on the growth of Trichoderma harzianum and Fuzarium oxysporum. J Appl Sci Res. 2007;3:350-455.

62. Khan WM, Prithiviraj B, Smiyh DL. Effect of foliar application of chitin oligosaccharides on photosynthesis of maize and soybean. Photosynthetica. 2002;40(4):621-624.

63. Chibu H, Shibayama H. Effects of chitosan application on the growth of several crops. In: T Uragami, et al. editors. Chitin and chitosan in life science. Japan; 2003. p. 235-239.

64. Lee SH, Choi S, Suh JS, et al. Oligogalacturonic acid and chitosan reduced stomatal aperture by inducing the evolution of reactive oxygen species from guard cell of tomato and commelina communis. Plant Physiol. 1999;121(1):147-152.

65. Paulino AT, Simionato IJ, Garcia JC, et al. Characterization of chitosan and chitin produced from silkworm chrysalides. Carbohydrate Polymers. 2006;64(1):98-103. 
66. Tauber OE. The distribution of chitin in an insect. Journal of Morphol ogy. 2005;56(1):51-58.

67. Mario FD, Rapana P, Tomati U, et al. Chitin and chitosan from Basidiomycetes. International Journal of Biological Macromolecules. 2008;43(1):8-12.

68. Yen MT, Mau JL. Physicochemical characterization of fungal chitosan from shiitake stipes. LWT Food Science and Technology. 2007;40:472479

69. Nwe N, Furuike T, Tamura H. Chitin and chitosan from terrestrial organisms, In: Kim SK editor. Chitin, Chitosan, Oligosaccharides and Their Derivatives:Biological Activities and Applications. Florida: Taylor and Francis Group LLC; 2010. p. 3-10.

70. Doares SH, Syrovets T, Wieler EW, et al. Oligogalacturonides and chitosan activate plant defensive gene through the octadecanoid pathway. PNAS. 1995;92(10):4095-4098.

71. Eikemo H, Stensvand A, Tronsmo AM. Induced resistance as a possible means to control dissease of strawberry caused by Phytophthora spp. Plant Disease. 2003;87(4):345-350.

72. Bell AA, Habbard JC, Liu L. Effect of chitin and chitosan on the incidence and severity of Fusarium Yellows of Celery. Plant Disease. 1998;82(3):322-328.

73. Bittelli M, Flury M, Campbell GS, et al. Reduction of transpiration through foliar application of chitosan. Agricultural and Forest Meteorology. 2001;107(3):167-175.

74. Hirano S, Yamamoto T, Hayashi M, et al. Chitinase activity in seeds coated with chitosan derivatives. Agricultural and Biological Chemistry. 1990;54(10):2719-2720.

75. Vasiukova NI, Zinoveva SV, Iiinskaia LI, et al. Modulation of plant resistance to diseases by water-soluble chitosan. Prikladnaia Biokhimiia Mikrobiologiia. 2001;37(1):115-122.

76. Khan W, Prithiviraj B, Smith DL. Chitosan and chitin oligomers increase phenylalanine ammonia-lyase and tyrosine. Journal of Plant Physiology. 2003;160(8):859-863.

77. XianLing JG, YingPing M, ZhiMei L, et al. Effect of chitosan on physiological and biochemical characteristic of seed germination and seedling of mulberry (Morus alba). Acta Sericologica Sinica. 2002;28(3):253255 .

78. Nicholson RL, Hamerschmidt R. Phenolic compounds and their role in disease resistance. Annu Rev Phytopathol. 1992;30:369-389.

79. Yue DYZ, Zhi MZ, Yong GQ, et al. Effect of chitosan on physiological activities in germinating seed and seedling leaves of maize. Journal of Habei Vocation - Technical Teachers College. 2001;15(4):9-12.

80. Nam-Soo J, Ganesh KA, Randeep P, et al. Differential regulation of an early and late responsive rice endosperm kinase mRNA in seedling leaves. Plant Physiology and Biochemistry. 2002;40(12):1025-1031.

81. Ohta K, Tanguchi A, Konishi N, et al. Chitosan treatment affects plant growth and flower quality in Eustoma grandiflorum. Hort Science. 1999;34(2):233-234.

82. Xue YS, Qing ZW, Wei X, et al. Effect of chitosan as seed coating on seed germination and seedling growth and several physiological and biochemical indexes in rapeseed. Plant Physiology Communication. 2002;38(3):225-227.

83. Chibu H, Shibayama H. Effects of chitosan applications on the early growth of several crops. Report of Kyushu Branch of the Crop Science Society of Japa. 1999;65:83-87.
84. Ouyang S, Langlai X. Effect of chitosan on nutrient quality and some agronomic characteristic of non-heading chinese cabbage. Plant Physiology Communication. 2003;39(1):21-24.

85. Utsunomiya N, Kinai H, Matsui Y, et al. The effects of chitosan oligosaccharides soil conditioner and nitrogen fertilizer on the flowering and fruit growth of purple passion fruit (Passiflora edulis Sims var. edulis). Journal of the Japanese Society for Horticultural Science. 1998;67(4):567571.

86. Harada JS, Arima H, Shibayama, et al. Effect of chitosan application on growth and seed yield of soybean. Marine and Highland Bioscience Center Report. 1995;2:15-19.

87. Krivtsov GG, Loskutova NA, Konyuknova NS, et al. Effect of chitosan elicitors on wheat plants. Biology Bulletin of the Russian Academy of Sciences. 1996;23(1):16-21.

88. Ali M, Horiuchi T, Miyakawa S. Nodulation, nitrogen fixation and growth of soybean plants (Glycine max Merr.) in soil supplemented with chitin or chitosan. Japanese Journal of Crop Science. 1997;66(1):100 107.

89. Loschke DC, Hadwiger LA, Wagoner W. Comparison of mRNA populations coding for phenylalanine ammonia lyase and other peptides from pea tissue treated with biotic and abiotic phytoalexin inducers. Physiol Plant Pathol. 1983;23(1):163-173.

90. Walker-Simmons M, Ryan CA. Proteinase inhibitor synthesis in tomato leaves. Plant Physiol. 1984;76:787-790.

91. Famer EE, Ryan CA. Interplant communication:airborne methyl jasmonate induces synthesis of protienase inhibitors in plant leaves. Proc Natl Acad Sci U.S.A. 1990;87(19):7713-7716.

92. Sembdner G, Parthier B. The biochemistry and the physiological and molecular actions of jasmonates. Plant Mol Biol. 1993;44:569-589.

93. Willmer CM, Pricker M. Stomata. 2nd ed. London: Champand Hall; 1996.

94. Leung J, Giraudat J. Abscisic acid and signal transduction. Plant Mol Biol. 1998;49:199-222.

95. Grill E, Ziegler H. A plant's dilemma. Science. 1998;282(5387):252253.

96. Jwaa N-S, Agrawal GK, Rakwal R, et al. Differential regulation of an early and late responsive rice endosperm kinase mRNA in seedling leaves. Plant Physiol Biochem. 2002;40(12):1025-1031.

97. Klusener B, Jared JY, Yoshiyuki M, et al. Convergence of calcium signaling pathway of pathogenic elicitors and abscissic acid in arabidopsis guard cells. Plant Physiol. 2002;130(4):2152-2163.

98. Tham LX, Nagasawa N, Matsuhashib S, et al. Effect of radiation-degraded chitosan on plants stressed with vanadium. Radiation Physics and Chemistry. 2001;61(2):171-175.

99. Aranaz I, Mengibar M, Harris R, et al. Functional characterization of chitin and chitosan. Curr Chem Biol. 2009;3:203-230.

100. Xia W, Liu P, Zhang J, et al. Biological activities of chitosan and chitooligosaccharides. Food Hydrocolloids. 2011;25(2):170-179.

101. Kim SK, Rajapakse N. Enzymatic production and biological activities of chitosan oligosaccharides (COS):A review. Carbohydr Polym 2005;62(4):357-368

102. Mourya VK, Inamdar NN, Choudhari YM. Chitooligosaccharides:Synthesis, characterization and applications. Polym Sci Ser A. 2011;53(7):583-612.

103. Cabrera JC, Van Cutsem P. Preparation of chitooligosaccharides with degree of polymerization higher than 6 by acid or enzymatic degradation of chitosan. Biochem Eng J. 2005;25(2):165-172. 
104. Zeng J, Zheng LY. Studies on Penicillium sp. ZDZ1 chitosanase immobilized on chitin by cross-linking reaction. Process Biochem. 2002;38(4):531-535.

105. Lin YW, Hsiao YC, Chiang BH. Production of high degree polymerized chitooligosaccharides in a membrane reactor using purified chitosanase from Bacillus cereus. Food Research International. 2009;42(9):13551361 .

106. Tokoro A, Tatewaki N, Suzuki K, et al. Growth inhibitory effect of hexa-N-acetylchitohexaose and chitohexaose. Chem Pharm Bull (Tokyo). 1988;36(2):784-790.
107. Zhao XR, Xia WS. Antimicrobial activities of chitosan and application in food preservation. Chinese Food Research and Development. 2006;27(2):157-160

108. Zheng LY, Zhu JF. Study on antimicrobial activity of chitosan with different molecular weights. Carbohydrate Polymers. 2003;54(4):527-530.

109. Yang TC, Chou CC, Li CF. Antibacterial activity of N-alkylated disaccharide chitosan derivatives. Int J Food Microbiol. 2005;97(3):237-245.

110. Jeon YJ, Kim SK. Effect of antimicrobial activity by chitosan oligosaccharide N-conjugated with asparagine. J Microbiology and Biotech. 2001;11(2):281-286 